\title{
Mobile Cardiac Outpatient Telemetry Patch vs Implantable Loop Recorder in Cryptogenic Stroke Patients in the US - Cost-Minimization Model
}

\author{
Goran Medic (D) $^{1,2}$ \\ Nikos Kotsopoulos ${ }^{3}$ \\ Mark P Connolly iD ${ }^{2,3}$ \\ Jennifer Lavelle ${ }^{4}$ \\ Vincent Norlock ${ }^{4}$ \\ Manish Wadhwa ${ }^{4}$ \\ Belinda A Mohr ${ }^{5}$ \\ Wayne M Derkac ${ }^{4}$ \\ 'Chief Medical Office, Philips Healthcare, \\ Eindhoven, Netherlands; ' ${ }^{2}$ Department of \\ Pharmacy, University of Groningen, \\ Groningen, Netherlands; ${ }^{3}$ Global Market \\ Access Solutions LLC, Charlotte, NC, \\ USA; ${ }^{4}$ BioTelemetry, Inc., A Philips \\ Company, Malvern, PA, USA; ${ }^{5}$ Chief \\ Medical Office, Philips, Cambridge, \\ MA, USA
}

Purpose: The aim of this study was to compare costs and outcomes of mobile cardiac outpatient telemetry (MCOT) patch followed by implantable loop recorder (ILR) compared to ILR alone in cryptogenic stroke patients from the US health-care payors' perspective.

Patients and Methods: A quantitative decision tree cost-minimization simulation model was developed. Eligible patients were 18 years of age or older and were diagnosed with having a cryptogenic stroke, without previously documented atrial fibrillation (AF). All patients were assigned first to one then to the alternative monitoring strategies. Following AF detection, patients were initiated on oral anticoagulants (OAC). The model assessed direct costs for one year attributed to MCOT patch followed by ILR or ILR alone using a monitoring duration of 30 days post-cryptogenic stroke.

Results: In the base case modeling, the MCOT patch arm detected 4.6 more patients with AFs compared to the ILR alone arm in a cohort of 1000 patients (209 vs 45 patients with detected AFs, respectively). Using MCOT patch followed by ILR in half of the patients initially undiagnosed with AF leads to significant cost savings of US $\$ 4,083,214$ compared to ILR alone in a cohort of 1000 patients. Cost per patient with detected AF was significantly lower in the MCOT patch arm $\$ 29,598$ vs $\$ 228,507$ in the ILR only arm.

Conclusion: An initial strategy of 30-day electrocardiogram (ECG) monitoring with MCOT patch in diagnosis of AF in cryptogenic stroke patients realizes significant cost-savings compared to proceeding directly to ILR only. Almost 8 times lower costs were achieved with improved detection rates and reduction of secondary stroke risk due to new anticoagulant use in subjects with MCOT patch detected AF. These results strengthen emerging recommendations for prolonged ECG monitoring in secondary stroke prevention.

Keywords: ambulatory cardiac monitoring, Holter, atrial fibrillation, electrocardiography, economic evaluation, secondary prevention

\section{Introduction}

The fifth leading cause of death in the United States (US) is stroke. Annual incidence of stroke is 795,000 patients. ${ }^{1}$ Stroke can be classified into two major subtypes: hemorrhagic, representing about $17 \%$ and ischemic, representing around $83 \%$ of patients. Of the ischemic strokes, approximately $15-40 \%$ are considered to be cryptogenic strokes, ischemic strokes with no identifiable etiology. ${ }^{1,2}$

Identifying the cause of a stroke in the one-third of patients suffering cryptogenic stroke is essential for the implementation of appropriate secondary stroke prevention strategies. ${ }^{1,3-5}$ Newly diagnosed atrial fibrillation (AF) is only identified
Correspondence: Goran Medic

Chief Medical Office, Philips Healthcare,

High Tech Campus 37-3.009, Eindhoven,

5656 AG, Netherlands

Tel +3I-6I-8I9-3782

Email goran.medic@philips.com 
in $\approx 5 \%$ of patients with stroke in the inpatient setting, ${ }^{6}$ but paroxysmal AF (PAF) may not be present at the time of the stroke or may escape detection during inpatient cardiac monitoring. ${ }^{7}$ Thus, outpatient cardiac monitoring is often used to improve the identification of PAF.

$\mathrm{AF}$ is defined as an episode of irregular heart rhythm, without detectable $\mathrm{P}$ waves, of any duration. ${ }^{8-10} \mathrm{AF}$ is associated with an increase in the risk of stroke, cardiovascular morbidity and mortality, and significant increases in the total cost of care and impairment in quality of life (QoL). ${ }^{11,12}$ Among patients with AF, those with a history of stroke carry the highest risk of recurrent stroke, with a $15 \%$ risk during the first year after stroke (2.5 times higher than in those without a previous stroke). ${ }^{13,14}$ Management of stroke in the setting of AF is expensive, with one source citing an annual cost of approximately $\$ 26$ billion. ${ }^{15}$ Additionally, the major risks associated with undetected AF, both persistent and paroxysmal, are ischemic stroke and other thromboembolic events, which could be prevented by a prompt diagnosis of AF and consequent oral anticoagulant (OAC) therapy. ${ }^{16-19}$ Early identification of $\mathrm{AF}$ and treatment with $\mathrm{OAC}$ will reduce the risk of recurrent stroke and death in both the primary or secondary prevention setting. ${ }^{20}$ The American Heart Association/American Stroke Association Guidelines recommend a confirmed diagnosis of AF following stroke before initiation of anticoagulant therapy whereas in the absence of proven AF, antiplatelet therapy is usually recommended. ${ }^{21}$

Atrial fibrillation can remain undetected in patients using the current standard of care (SoC) for AF detection electrocardiogram (ECG) monitoring for at least $24 \mathrm{~h}$ after a stroke. $^{22-24}$ To detect AF, recommendations from the American Academy of Neurology suggest monitoring cardiac rhythm for prolonged periods, often for periods longer than 1 week, instead of shorter periods (ie, 24 hours) in patients with cryptogenic stroke without known AF. $^{25}$

Clinicians have several monitoring options offering different monitoring periods, detection rates and costs. Common monitoring solutions include: Holter monitors (short-term (24-48h) and long-term (1-2 weeks)), postevent recorders (non-looping recorders), external loop recorders (ELR), mobile cardiac outpatient telemetry (MCOT), and implantable loop recorders (ILR). ${ }^{26}$ Due to variation in the costs and outcomes, an economic evaluation comparing some of these options would inform treatment choices and health system efficiency. Therefore, the analysis described here focused on a post-stroke population in which options included monitoring with MCOT $^{\circledR}$ patch (BioTelemetry Inc, a Philips company, Malvern, PA, USA) for 30 days possibly followed by ILR if AF is not diagnosed or ILR monitoring only with evaluation of up to the first 30 days of monitoring.

\section{Materials and Methods}

The aim of this economic analysis was to assess the costs associated with MCOT patch followed by ILR, compared to ILR alone in cryptogenic stroke patients from the US payors' perspective.

We designed a quantitative decision-tree simulation model with base values identified through targeted literature reviews. The analysis described will aid clinicians and hospital procurement staff to optimize patient outcomes and improve health system efficiency.

Several targeted literature searches were performed to obtain source data on costs, the probability of different events occurring, different model designs, modeling assumptions, current standard medical practice for monitoring cryptogenic stroke patients and different international medical guidelines. Search terms used to identify articles in PubMed included: disease terms (ischemic stroke, atrial fibrillation), intervention terms (cardiac monitoring, electrocardiography) and health economics terms (cost-minimization analysis, cost-effectiveness analysis, cost-benefit analysis, cost-utility analysis). Search strategies were restricted to publications written in English. There were no time restrictions for studies; however, most recently published studies were preferred. The main inclusion criteria were: cryptogenic stroke patients based in the USA wearing either MCOT or ILR.

\section{Model Structure}

Figure 1 illustrates the model structure used for quantifying costs and outcomes at every stage of monitoring and treatment. There are two diagnostic and monitoring arms in the model:

- MCOT patch arm: MCOT patch followed by ILR in undetected AF patients for 30 days;

- ILR arm: ILR alone evaluating first 30 days of monitoring.

Eligible patients were 18 years of age or older and were diagnosed with cryptogenic stroke, without previously documented $\mathrm{AF}$ at the time of index presentation or 


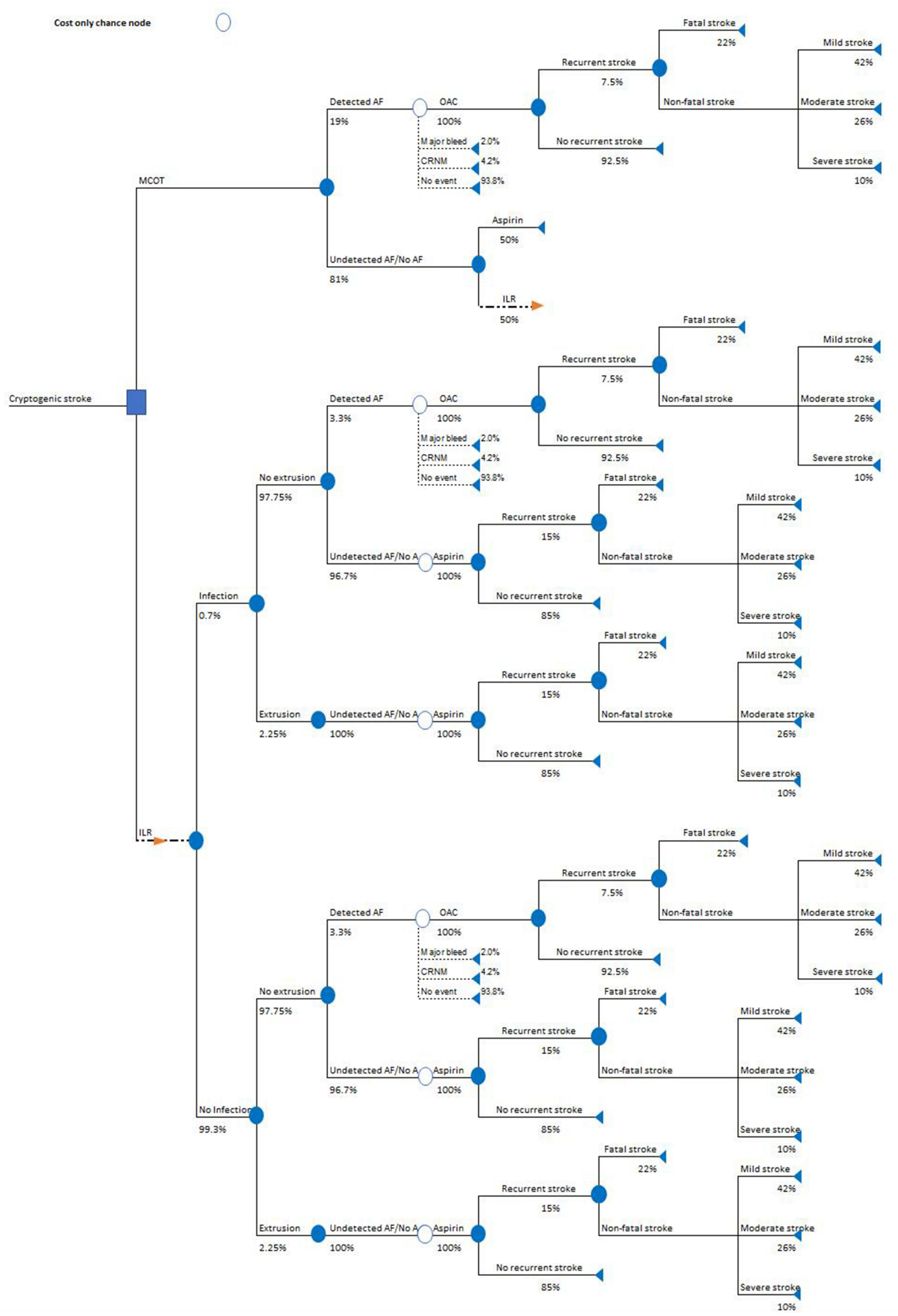

Figure I Model structure.

Abbreviations: AF, atrial fibrillation; CRNM, clinically relevant non-major; ILR, implantable loop recorder; MCOT, mobile cardiac outpatient telemetry; OAC, oral anticoagulant. 
following in-hospital Holter monitoring, and for whom additional cardiac monitoring would be desired to screen further for the possibility of paroxysmal AF.

A quantitative decision tree cost-minimization simulation model was developed in Microsoft Excel applying a oneyear time horizon without discounting of costs or outcome.

\section{Model Assumptions}

Several assumptions were applied in the model consistent with previous studies, identified through a targeted literature review, reporting costs of stroke prevention in patients with $\mathrm{AF}: 27,28$

1. All patients entered the model with "no underlying AF" or "occult AF not detected." Depending on the diagnostic performance of the allocated ECG monitoring strategy, AF was subsequently detected, and patients were initiated on appropriate therapy (ie, anticoagulation with OACs).

2. The diagnostic yield of devices was constant for a 30-day period. The cumulative probability of diagnosis of post-stroke AF for MCOT was taken from a meta-analysis performed by Sposato et al 2015. ${ }^{29}$ The cumulative probability of diagnosis of post-stroke AF for ILR was taken from the Ziegler et al 2015 study. $^{30}$

3. The selection of antithrombotic agents for secondary stroke prevention in patients who were found to have AF after cryptogenic stroke was at the discretion of their treating physician.

4. Absence of stroke implied that no additional costs other than monitoring were accrued. Therefore, we did not calculate any costs for those patients that did not have recurrent strokes and ongoing management costs.

5. AF was defined as AF of any duration based on study treatment protocol of a large number of cryptogenic stroke patients diagnosed with AF. These stroke patients, in whom AF of any duration was diagnosed, were all advised to begin anticoagulation unless clinical contraindications existed. ${ }^{31}$

6. The percentage of patients using oral anticoagulants and aspirin was the same. However, two scenarios were considered:

a. Base case: $100 \%$ for both aspirin and OAC Assumption.

b. Scenario 1: $84 \%$ for both aspirin and OAC based on Favilla et al $2015^{31}$
7. The cost analysis assumed $100 \%$ treatment compliance

8. The time horizon of the model was 1 year post cryptogenic stroke.

9. All four OACs (dabigatran, rivaroxaban, apixaban, edoxaban) applied in the model were considered to have the same/similar efficacy.

10. All patients with newly detected AF receiving OAC in the study would derive the same clinical benefit regarding secondary stroke prevention.

11. Cryptogenic stroke was assumed to be similar/same for all patients. Therefore, the size, severity of stroke and the risk of recurrent bleeding were not taken into account.

\section{Perspective and Time Horizon}

The economic analysis of this model was performed from a US payor perspective including only direct medical costs. The current model assesses the costs accrued with MCOT patch followed by ILR or ILR alone using a monitoring time of 30 days and a time horizon of one year post-cryptogenic stroke.

\section{Input Parameters}

The dosages of OACs were aligned with the dosages prescribed in the summary of product characteristics. The acquisition costs were obtained for the smallest pack size. In our model, all patients started treatment with aspirin. OACs were initiated only upon AF detection. Of those receiving anticoagulant therapy (dabigatran, rivaroxaban, apixaban, edoxaban), an average price of all four drugs was used. The costs were inflated from the published cost year to 2021 levels using the Medical Consumer Price Index as reported by the US Bureau of Labor Statistics. $^{32}$ An overview of all cost inputs used in the model is provided in Table 1 .

\section{Event Probabilities}

Event probabilities used in the model are shown in Table 2. Values were derived from published studies identified through targeted literature review. All-cause mortality rates were derived from Sawyer et al. ${ }^{33}$

Depending on the diagnostic performance of the allocated monitoring strategy, AF was subsequently detected, and patients were initiated on appropriate therapy (ie, $\mathrm{OACs}$ ). If subsequent testing for AF was non-diagnostic, patients received aspirin alone (Figure 1). To account for differences in costs, and post-stroke mortality, we further 
Table I Model Input Parameters - Costs

\begin{tabular}{|c|c|c|c|}
\hline Parameter & $\begin{array}{l}\text { Value Used in the Model } \\
\text { (Inflated to 202 I Values) }\end{array}$ & $\begin{array}{l}\text { Original } \\
\text { Value } \\
\text { (Year) }\end{array}$ & Reference \\
\hline \multicolumn{4}{|l|}{ DRUG COSTS - I month therapy } \\
\hline Aspirin (108x8Img) & $\$ 3.20$ & $\mathrm{~N} / \mathrm{A}$ & {$[40]$} \\
\hline Dabigatran & $\$ 320.96$ & $\begin{array}{l}\$ 296.06 \\
(2018)\end{array}$ & {$[4 I]$} \\
\hline Rivaroxaban & $\$ 335.64$ & $\begin{array}{l}\$ 309.60 \\
(2018)\end{array}$ & {$[4 I]$} \\
\hline Apixaban & $\$ 336.01$ & $\begin{array}{l}\$ 309.94 \\
(2018)\end{array}$ & {$[4 I]$} \\
\hline Edoxaban & $\$ 272.00$ & $\begin{array}{l}\$ 250.90 \\
(2018)\end{array}$ & {$[4 I]$} \\
\hline $\begin{array}{l}\text { Average price of OAC (dabigatran, } \\
\text { rivaroxaban, apixaban, edoxaban) }\end{array}$ & $\$ 316.15$ & N/A & Calculation \\
\hline \multicolumn{4}{|l|}{ STROKE COSTS } \\
\hline Recurrent mild stroke & $\$ 14,657.50$ & $\begin{array}{l}\$ 12,398.00 \\
(2015)\end{array}$ & {$[42]$} \\
\hline Recurrent moderate stroke & $\$ 31,031.62$ & $\begin{array}{l}\$ 26,248.00 \\
(2015)\end{array}$ & {$[42]$} \\
\hline Recurrent severe stroke & $\$ 71,893.62$ & $\begin{array}{l}\$ 60,811.00 \\
(2015)\end{array}$ & {$[42]$} \\
\hline Recurrent fatal stroke/death & $\$ 35,123.37$ & $\begin{array}{l}\$ 29,709.00 \\
(2015)\end{array}$ & {$[42]$} \\
\hline \multicolumn{4}{|l|}{ COST OF INFECTIONS } \\
\hline $\begin{array}{l}\text { Risk-adjusted cost for Superficial Surgical } \\
\text { site infections }\end{array}$ & $\$ 9,507.73$ & $\begin{array}{l}\$ 7,003.00 \\
(2010)\end{array}$ & [43] \\
\hline \multicolumn{4}{|l|}{ BLEEDING COSTS } \\
\hline Major bleeding & $\$ 20,750.52$ & $\begin{array}{l}\$ 19,469.00 \\
(2019)\end{array}$ & {$[44]$} \\
\hline CRNM bleed event & $\$ 5,201.22$ & $\begin{array}{l}\$ 4,880.00 \\
(2019)\end{array}$ & {$[44]$} \\
\hline \multicolumn{4}{|l|}{ MCOT COSTS } \\
\hline Professional Fee & $\$ 27.92$ & $\begin{array}{l}\$ 27.43 \\
(2020)\end{array}$ & $\begin{array}{l}\text { CPT: } 93,228 \\
\text { CMS Physician Fee Schedule } 2020 \text { (National } \\
\text { Average) } \\
\text { https://www.cms.gov/apps/physician-fee-schedule } \\
\text { /search/search-criteria.aspx }\end{array}$ \\
\hline Technical Fee & $\$ 728.32$ & $\begin{array}{l}\$ 715.66 \\
(2020)\end{array}$ & CPT 93229 \\
\hline Total MCOT Cost: & $\$ 756.24$ & $\$ 743.09$ & \\
\hline
\end{tabular}


Table I (Continued).

\begin{tabular}{|c|c|c|c|}
\hline Parameter & $\begin{array}{l}\text { Value Used in the Model } \\
\text { (Inflated to 202I Values) }\end{array}$ & $\begin{array}{l}\text { Original } \\
\text { Value } \\
\text { (Year) }\end{array}$ & Reference \\
\hline \multicolumn{4}{|l|}{ ILR COSTS } \\
\hline Professional Fee & $\$ 28.65$ & $\$ 28.15$ & $\begin{array}{l}\text { CPT: 93,298 } \\
\text { CMS Physician Fee Schedule } 2020 \text { (National } \\
\text { Average) } \\
\text { https://www.cms.gov/apps/physician-fee-schedule } \\
\text { /search/search-criteria.aspx } \\
\text { This accounts for I/I2th of the fee (for I month } \\
\text { only) }\end{array}$ \\
\hline Technical Fee & $\$ 280.26$ & $\$ 275.39$ & $\begin{array}{l}\text { CPT: G2066 } \\
\text { G2066 is Carrier Priced. Above rate is based on NY } \\
\text { Locality } 2 \text { Physician Fee Schedule [LINK] } \\
\text { This accounts for I/I } 2 \text { th of the fee (for I month } \\
\text { only) }\end{array}$ \\
\hline Insertion of ILR & $\$ 5,250.64$ & $\$ 5,159.37$ & $\begin{array}{l}\text { CPT: } 33,285 \\
\text { This accounts for the whole fee. }\end{array}$ \\
\hline Removal of ILR & $\$ 139.93$ & $\$ 137.50$ & $\begin{array}{l}\text { CPT: } 33,286 \\
\text { This accounts for the whole fee. }\end{array}$ \\
\hline Total ILR Cost: & $\$ 5,699.48$ & $\$ 5,600.41$ & \\
\hline
\end{tabular}

Abbreviations: CMS, Centers for Medicare \& Medicaid Services; CPT, current procedural terminology; Gl, gastrointestinal; ILR, implantable loop recorder; MCOT, mobile cardiac outpatient telemetry; OAC, oral anticoagulant.

stratified the patients based on mild, moderate, or severe post-stroke classified by the Modified Rankin Scale (mRS). The mild, moderate, and severe cases were defined as a mRS score of $0-2,3-4$, and 5 , respectively.

At any point, there was a risk that patients experience an adverse event, such as bleeding as a side-effect of OAC therapy. Bleeding events incorporated into the model included major bleeding and clinically relevant nonmajor (CRNM) bleeds.

\section{Analyses}

The analysis quantifies the cumulative one-year costs following the initial treatment choice between MCOT and ILR and the incremental cost difference.

The results of the model will be presented for the base case and 3 different scenario analyses. An overview of the differences among base case and scenarios can be found in Table 3 .

Parameter uncertainty was explored by use of deterministic one-way sensitivity analyses (OWSAs). Fundamental clinical input parameters were individually varied as $\pm 25 \%$ (user-modifiable) of the point estimate for event probabilities.

\section{Model Outcomes}

The primary model outcome was the difference in total costs between MCOT patch and ILR only arms for the whole cohort of 1000 patients. Relevant secondary outcomes included: difference in costs per AF detected, average cost per one patient monitored, incremental recurrent strokes avoided and incremental infections avoided using MCOT patch vs ILR only arms.

\section{Results}

\section{Base Case Results}

The results of the base case economic analysis (per diagnosis arm and incremental results) are displayed in Tables 4 and 5 .

Using the MCOT patch followed by ILR as the first choice for diagnosing AF after cryptogenic stroke leads to significant cost savings compared to ILR alone. The MCOT patch arm detected 4.6 times more patients with AF compared to the ILR alone arm based on a cohort of 1000 patients (209 vs 45 patients with detected AF respectively). The number of bleeding events was higher in the MCOT patch arm because more 
Table 2 Model Input Parameters - Event Probabilities

\begin{tabular}{|c|c|c|}
\hline Parameter & $\begin{array}{l}\text { Value Used in the } \\
\text { Model }\end{array}$ & Reference \\
\hline \multicolumn{3}{|l|}{ Stroke-related probabilities } \\
\hline Recurrent mild stroke & $42 \%$ & [33] \\
\hline Recurrent moderate stroke & $26 \%$ & [33] \\
\hline Recurrent severe stroke & $10 \%$ & [33] \\
\hline Recurrent fatal stroke/death & $22 \%$ & [33] \\
\hline Recurrent stroke in Ist year without OAC & $15 \%$ & {$[13,14]$} \\
\hline Recurrent stroke in Ist year with OAC & $7.50 \%$ & [24] \\
\hline \multicolumn{3}{|l|}{ Infection rate ILR } \\
\hline Infection rate after ILR & $0.7 \%$ & {$[45]$} \\
\hline \multicolumn{3}{|l|}{ Extrusion rate ILR } \\
\hline Extrusion rate after ILR & $2.25 \%$ & {$[45]$} \\
\hline \multicolumn{3}{|l|}{ Bleedings } \\
\hline $\begin{array}{l}\text { Annual bleeding rate combined (average from dabigatran, rivaroxaban, apixaban, } \\
\text { edoxaban) }\end{array}$ & $2.9 \%$ & [46] \\
\hline Major bleeding & $2.02 \%$ & [44] \\
\hline CRNM bleed event & $4.18 \%$ & [44] \\
\hline \multicolumn{3}{|l|}{ Detection rates } \\
\hline Detected AF MCOT & $19.10 \%$ & [29] \\
\hline No AF/Undetected AF [MCOT] & $80.90 \%$ & $\begin{array}{l}\text { Calculation based on Sposato et al } \\
2015^{29}\end{array}$ \\
\hline Detected AF ILR & $4.60 \%$ & [30] \\
\hline No AF/Undetected AF [ILR] & $95.40 \%$ & $\begin{array}{l}\text { Calculation based on Ziegler et al } \\
2015^{30}\end{array}$ \\
\hline No AF/Undetected AF [ILR] - After extrusion & $100.00 \%$ & Assumption \\
\hline \multicolumn{3}{|l|}{ Drug usage probabilities } \\
\hline OAC usage post-detection of $\mathrm{AF}$ (base case) & $100 \%$ & Assumption \\
\hline Aspirin usage (base case) & $100 \%$ & Assumption \\
\hline OAC usage post-detection of AF (scenario analysis) & $84 \%$ & {$[31]$} \\
\hline Aspirin usage (scenario analysis) & $84 \%$ & [31] \\
\hline \multicolumn{3}{|l|}{ Other } \\
\hline Percentage of patients getting ILR after MCOT and undetected AF or No AF & $50-60 \%$ & KOL opinion \\
\hline
\end{tabular}

Abbreviations: AF, atrial fibrillation; CMS, Centers for Medicare \& Medicaid Services; CPT, current procedural terminology; CRNM, clinically relevant non-major; GI, gastrointestinal; ILR, implantable loop recorder; MCOT, mobile cardiac outpatient telemetry; OAC, oral anticoagulant. 
Table 3 Overview of Model Scenarios

\begin{tabular}{|c|c|c|c|c|}
\hline & Base Case & Scenario I & Scenario 2 & Scenario 3 \\
\hline Percentage of patients getting ILR after MCOT and undetected AF or No AF & $50 \%$ & $50 \%$ & $60 \%$ & $60 \%$ \\
\hline OAC usage post-detection of $\mathrm{AF}$ & $100 \%$ & $84 \%$ & $100 \%$ & $84 \%$ \\
\hline Aspirin usage & $100 \%$ & $84 \%$ & $100 \%$ & $84 \%$ \\
\hline
\end{tabular}

Abbreviations: AF, atrial fibrillation; ILR, implantable loop recorder; MCOT, mobile cardiac outpatient telemetry; OAC, oral anticoagulant.

Table 4 Base Case - Clinical Results for a Cohort of 1000 Patients

\begin{tabular}{|c|c|c|c|}
\hline & $\begin{array}{l}\text { MCOT Patch Followed by } \\
\text { ILR* }\end{array}$ & ILR & $\begin{array}{l}\text { Difference MCOT Patch - } \\
\text { ILR }\end{array}$ \\
\hline $\begin{array}{l}\text { Number of patients with detected AFs in a cohort of } 1000 \\
\text { patients }\end{array}$ & 209 & 45 & 164 \\
\hline \multicolumn{4}{|l|}{ Strokes } \\
\hline Number of Recurrent Mild Strokes & 30.9 & 61.6 & -30.7 \\
\hline Number of Recurrent Moderate Strokes & 19.1 & 38.1 & -19.0 \\
\hline Number of Recurrent Severe Strokes & 7.4 & 14.7 & -7.3 \\
\hline Number of Recurrent Fatal Strokes/Deaths & 16.2 & 32.3 & -16.1 \\
\hline Total number of Recurrent Strokes & 73.6 & 146.6 & -73.0 \\
\hline \multicolumn{4}{|l|}{ Bleedings } \\
\hline Number of Major bleedings & 4.2 & 0.9 & 3.3 \\
\hline Number of CRNM bleed events & 8.7 & 1.9 & 6.9 \\
\hline Total Number of bleedings & 13.0 & 2.8 & 10.2 \\
\hline \multicolumn{4}{|l|}{ Infections/extrusions } \\
\hline Number of infections & 2.83 & 7.00 & -4.17 \\
\hline Number of extrusions & 9.10 & 22.50 & -13.40 \\
\hline
\end{tabular}

Note: *Percentage of undetected AF patients in MCOT patch group receive ILR for diagnosis.

Abbreviations: AF, atrial fibrillation; CRNM, clinically relevant non-major; ILR, implantable loop recorder; MCOT, mobile cardiac outpatient telemetry.

detected AF patients were started on OACs (13 vs 2.8 bleeding events, respectively, on a cohort of 1000).

We estimate that 16 fatal strokes were avoided in a cohort of 1000 patients annually for those diagnosed with MCOT compared to ILR.

The cost per patient with detected AF was significantly lower in the MCOT patch arm than in the ILR arm (\$29,598 vs $\$ 228,507$, respectively). The average cost per patient monitored with MCOT followed by ILR compared to ILR alone was $\$ 6,192$ vs $\$ 10,275$, respectively.

\section{Model Uncertainty}

Varying important clinical parameters in the model influenced the incremental cost savings between both treatment arms (Figure 2). The incremental cost savings was most sensitive to the percentage of undetected AF in patients receiving ILR after MCOT and undetected AF, followed by recurrent stroke without OAC (when only aspirin is given). Varying the proportion of infection rates, major bleeding with ILR and CRNM bleeding had limited influence on the conclusions of the base case analysis. 
Table 5 Base Case - Economic Results for a Cohort of 1000 Patients

\begin{tabular}{|l|c|c|c|}
\hline & $\begin{array}{c}\text { MCOT Patch Followed by } \\
\text { ILR* }\end{array}$ & ILR & $\begin{array}{c}\text { Difference MCOT Patch - } \\
\text { ILR }\end{array}$ \\
\hline Device & $\$ 3,061,680$ & $\$ 5,699,480$ & $-\$ 2,637,800$ \\
\hline Fatal strokes/Death & $\$ 568,995$ & $\$ 1,133,013$ & $-\$ 564,018$ \\
\hline Recurrent strokes & $\$ 1,576,819$ & $\$ 3,139,845$ & $-\$ 39,633$ \\
\hline Infections & $\$ 26,921$ & $\$ 66,554$ & $\$ 104,540$ \\
\hline Bleeding events & $\$ 133,163$ & $\$ 28,623$ & $-\$ 6,313$ \\
\hline Aspirin costs & $\$ 30,399$ & $\$ 36,712$ & $\$ 623,035$ \\
\hline OAC costs & $\$ 793,625$ & $\$ 170,590$ & $-\$ 4,083,214$ \\
\hline Total costs & $\$ 6,191,602$ & $\$ 10,274,816$ & $-\$ 198,909$ \\
\hline $\begin{array}{l}\text { Cost per patient with detected } \\
\text { AF }\end{array}$ & $\$ 29,598$ & $\$ 228,507$ & $-\$ 4,083$ \\
\hline Cost per I patient monitored & $\$ 6,192$ & $\$ 10,275$ & \\
\hline
\end{tabular}

Note: *Percentage of undetected AF patients in MCOT patch group receive ILR for diagnosis.

Abbreviations: AF, atrial fibrillation; ILR, implantable loop recorder; MCOT, mobile cardiac outpatient telemetry; OAC, oral anticoagulant.

\section{Scenario Analyses}

Scenario analyses were performed to investigate the impact on the total cost difference and number of detected patients with AF by varying the following parameters:

- Percentage of patients getting ILR after MCOT and undetected AF from $50 \%$ to $60 \%$ (Scenarios 2 and 3; Table 3);

- Changing OAC and aspirin usage from $100 \%$ in the base case to $84 \%$ based on Favilla et al 2015 study (Scenarios 1 and 3; Table 3). ${ }^{31}$

An overview of the clinical results of the difference between the MCOT patch arm and the ILR arm is presented in Table 6. Total cost differences between the two arms are also presented in Table 6 for all three scenarios. The highest impact on the total cost difference is an increase in the percentage of patients getting ILR after MCOT and undetected AF from $50 \%$ to $60 \%$. However, this increase in costs did not lead to significantly more patients with detected $\mathrm{AF}$ and led to $>10 \%$ increase in costs per patient with detected AF.

To summarize, base case results were confirmed by all three scenarios. Therefore, the results showed that 30-day ECG monitoring and diagnosis of $\mathrm{AF}$ in cryptogenic stroke patients with an MCOT patch arm, as the first choice, is cost-saving compared to ILR only arm.

\section{Discussion}

Conducting a cost analysis of AF poses technical and operational challenges as higher detection rates will lead to increased costs. In the analysis described here, the acquisition costs of MCOT are less than ILR; however, the improved detection rate with MCOT leads to higher costs associated with stroke prevention, but lower costs associated with stroke events. As is often the case in healthcare, investments in one technology can generate other health system costs and savings. This highlights the importance of conducting a comprehensive cost analysis taking into consideration the full range of costs and consequences. The success of a diagnostic and monitoring strategy is determined by the performance of the diagnostic tool and by the impact that an accurate and timely diagnosis can have on treatment and subsequent health events. In our model, we used AF episodes of any duration. As described here, the MCOT patch is associated with an approximate four-fold higher rate of patients with AF detection compared with ILR over 30 days of monitoring. This could be due to the studies showing a delay in the start of ILR monitoring as compared to the start of cardiac monitoring. ${ }^{29}$ Additionally, it could be affected by AF detection criteria as AF episodes less than 2 minutes in duration are not detected by the ILR algorithm. ${ }^{30}$ In the model, this resulted in more patients with detected $\mathrm{AF}$, fewer recurrent strokes and fewer deaths 
Percentage of patients getting ILR after MCOT and undetected AF or No AF

Recurrent stroke without OAC (Aspirin only)

Recurrent Moderate stroke

Recurrent Fatal Stroke/Death

Recurrent Severe stroke

Recurrent Mild stroke

Recurrent stroke in 1st year with OAC

Detected AF MCOT

Detected AF ILR - No extrusion

Major bleeding

Infection rate after ILR

CRNM bleed event

Extrusion rate after ILR

\begin{tabular}{|c|c|c|c|c|c|}
\hline \multirow[t]{2}{*}{$-\$ 5,50$} & $-\$ 5,00$ & $-\$ 4,50$ & $-\$ 4,00$ & $-\$ 3,50$ & $-\$ 3,00$ \\
\hline & \multicolumn{4}{|c|}{ Cost difference } & ons \\
\hline
\end{tabular}

a High $\mathbf{n}$ Low

Figure 2 Incremental results one-way sensitivity analysis - Base case.

Abbreviations: AF, atrial fibrillation; CRNM, clinically relevant non-major; ILR, implantable loop recorder; MCOT, mobile cardiac outpatient telemetry; OAC, oral anticoagulant.

compared with ILR. Consequently, due to improved AF detection, the costs associated with oral anticoagulants and bleeding events were higher in the MCOT managed subjects due to increased oral anticoagulant usage. These costs were offset by savings associated with a reduction in recurrent stroke events and lower device costs. All patients with newly detected AF (regardless of duration) receiving any of the available $\mathrm{OAC}$ in the study would derive the same clinical benefit regarding secondary stroke prevention. In the real-world setting, this assumption would need to be validated and tested.

Other studies have examined the cost-effectiveness of ILR but have used a time horizon of over a lifetime, ${ }^{24,33-35}$ which is not relevant to our one-year timeframe. No prior modeling study has examined the costs of MCOT from the US perspective. However, study by Tsang et al 2014 conducted a retrospective database analysis comparing MCOT to Event or Holter monitors in the US. ${ }^{36}$ This study came to the similar conclusion like our study that hospitals should be promoting the use of MCOT over Event or the Holter monitors. ${ }^{36}$ Another study, Kaura et al 2016, examined the costs of MCOT from the UK perspective. ${ }^{37}$ One study, Yong et al 2016, compared different monitoring durations from Canadian perspective. ${ }^{38}$ The conclusion from Yong et al's 2016 study is in line with our conclusion, meaning that in patients after a cryptogenic stroke, 30-day ECG monitoring is likely to be cost-effective for preventing recurrent strokes. ${ }^{38}$ Our study is unique in that it 
Table 6 Clinical and Economic Results (Difference MCOT Patch - ILR) for a Cohort of I000 Patients - Scenarios I, 2 and 3

\begin{tabular}{|c|c|c|c|}
\hline & Scenario I & Scenario 2 & Scenario 3 \\
\hline Number of patients with detected AFs & 164 & 168 & 168 \\
\hline \multicolumn{4}{|l|}{ Strokes } \\
\hline Number of Mild Strokes & -30.7 & -25.7 & -25.7 \\
\hline Number of Moderate Strokes & -19.0 & -15.9 & -15.9 \\
\hline Number of Severe Strokes & -7.3 & -6.1 & -6.1 \\
\hline Number of fatal strokes/deaths & -16.1 & -13.4 & -13.4 \\
\hline Total number of strokes & -73.0 & -61.1 & -61.1 \\
\hline \multicolumn{4}{|l|}{ Bleedings } \\
\hline Number of Major bleedings & 2.8 & 3.4 & 2.8 \\
\hline Number of CRNM bleed events & 5.8 & 7.0 & 5.9 \\
\hline Total Number of bleedings & 8.6 & 10.4 & 8.7 \\
\hline \multicolumn{4}{|l|}{ Infections/extrusions } \\
\hline Number of infections & -4.17 & -3.60 & -3.60 \\
\hline Number of extrusions & -13.40 & -11.58 & -11.58 \\
\hline \multicolumn{4}{|l|}{ Economic results } \\
\hline Device & $-\$ 2,637,800$ & $-\$ 2, \mid 76,712$ & $-\$ 2,176,712$ \\
\hline Fatal strokes/Death & $-\$ 564,018$ & $-\$ 472,357$ & $-\$ 472,357$ \\
\hline Recurrent strokes & $-\$ 1,563,026$ & $-\$ 1,309,012$ & $-\$ 1,309,012$ \\
\hline Infections & $-\$ 39,633$ & $-\$ 34,249$ & $-\$ 34,249$ \\
\hline Bleeding events & $\$ 87,814$ & $\$ 106,856$ & $\$ 89,759$ \\
\hline Aspirin costs & $-\$ 2,815$ & $-\$ 6,453$ & $-\$ 3,430$ \\
\hline OAC costs & $\$ 523,350$ & $\$ 636,836$ & $\$ 534,942$ \\
\hline Total costs & $-\$ 4,196,128$ & $-\$ 3,255,091$ & $-\$ 3,371,059$ \\
\hline Cost per patients with detected AF & $-\$ 198,789$ & $-\$ 195,524$ & $-\$ 195,406$ \\
\hline Cost per I patient monitored & $-\$ 4,196$ & $-\$ 3,255$ & $-\$ 3,371$ \\
\hline
\end{tabular}

Abbreviations: AF, atrial fibrillation; CRNM, clinically relevant non-major; ILR, implantable loop recorder; MCOT, mobile cardiac outpatient telemetry; OAC, oral anticoagulant.

compares two diagnostic strategies that have not been compared previously from the US cost perspective in a cost-minimization analysis.

Despite applying standard methodological approaches to our analysis, the study had several limitations that are worth taking into consideration when applying our results in practice. Firstly, the cost analysis considered only a 1-year time horizon for calculating costs and event rates. As strokes can occur after 1-year, extending the analysis to future years would influence the results Secondly, monitoring period for ILR is 30 -days, but this technology is worn for much longer. Limiting the monitoring period for ILR was done to ensure consistency in monitoring time across technologies. Thirdly, the selection of antithrombotic agent for secondary stroke prevention in patients who were found to have AF after cryptogenic stroke was at the discretion of their treating physician. The analysis did not consider any drug-specific differences 
in efficacy which could influence the results described here. Cryptogenic stroke was assumed to be similar/same for all patients. Therefore, the size, severity of stroke and the risk of recurrent bleeding were not taken into account. Furthermore, use of a payor perspective means that our model does not capture the societal costs of recurrent strokes from lost productivity. The inclusion of lost productivity would have a significant impact on our results considered the likely work loss and carer time associated with caring for people with strokes. ${ }^{39}$

Our findings have implications for both clinicians and policymakers that can improve health system efficiency. Cryptogenic stroke patients are common in everyday stroke practice. ${ }^{38}$ With practice guidelines now recommending longer than 1 week of monitoring cardiac rhythm to detect $\mathrm{AF}$ after cryptogenic stroke, ${ }^{25}$ our results support the recommendation that 30-day MCOT monitoring be made available to cryptogenic stroke patients. Use of MCOT as the first-line evaluation of cryptogenic stroke patients would further the goal of optimizing secondary stroke prevention by identifying as many patients with atrial fibrillation as possible at the lowest cost per identifiable $\mathrm{AF}$ and at the highest quality of life for these patients.

\section{Conclusion}

The results of this cost-minimization analysis indicate that 30-day ECG monitoring and diagnosis of AF in cryptogenic stroke patients with MCOT patch arm as an initial diagnostic strategy is cost-saving compared to proceeding directly to ILR only. Cost-savings were achieved due to improved detection rates and subsequent prevention of future strokes in subjects monitored with MCOT patch. These results strengthen emerging recommendations for prolonged ECG monitoring in secondary stroke prevention.

\section{Author Contributions}

All authors made a significant contribution to the work reported, whether that is in the conception, study design, execution, acquisition of data, analysis and interpretation, or in all these areas; took part in drafting, revising or critically reviewing the article; gave final approval of the version to be published; have agreed on the journal to which the article has been submitted; and agree to be accountable for all aspects of the work.

\section{Funding}

Philips funded all research activities for this work.

\section{Disclosure}

GM, JL, VN, MW, BAM and WMD are the employees of Philips. MW is the Chief Medical Officer for Biotelemetry, a producer of MCOT. NK and MPC are the employees of Global Market Access Solutions LLC. Global Market Access Solutions LLC received funding from Philips to build costminimization model and write the manuscript. The authors report no other conflicts of interest in relation to this work.

\section{References}

1. Benjamin EJ, Muntner P, Alonso A, et al. Heart disease and stroke statistics-2019 update: a report from the American Heart Association. Circulation. 2019;139(10):e56-e528. doi:10.1161/CIR.0000000000 000659

2. Serhal M, Mendirichaga M. Evaluation of cryptogenic stroke; 2019. Available from: https://www.acc.org/latest-in-cardiology/articles/ 2019/10/10/23/20/evaluation-of-cryptogenic-stroke. Accessed May 6, 2021.

3. Adams HP Jr, Bendixen BH, Kappelle LJ, et al. Classification of subtype of acute ischemic stroke. Definitions for use in a multicenter clinical trial. TOAST. Trial of Org 10172 in acute stroke treatment. Stroke. 1993;24(1):35-41. doi:10.1161/01.STR.24.1.35

4. Petty GW, Brown RD Jr, Whisnant JP, Sicks JD, O'Fallon WM, Wiebers DO. Ischemic stroke subtypes: a population-based study of incidence and risk factors. Stroke. 1999;30(12):2513-2516. doi:10.1161/01.STR.30.12.2513

5. Grau AJ, Weimar C, Buggle F, et al. Risk factors, outcome, and treatment in subtypes of ischemic stroke: the German stroke data bank. Stroke. 2001;32(11):2559-2566. doi:10.1161/hs1101.098524

6. Liao J, Khalid Z, Scallan C, Morillo C, O'Donnell M. Noninvasive cardiac monitoring for detecting paroxysmal atrial fibrillation or flutter after acute ischemic stroke: a systematic review. Stroke. 2007;38(11):2935-2940. doi:10.1161/STROKEAHA.106.478685

7. Bhatt A, Majid A, Razak A, Kassab M, Hussain S, Safdar A. Predictors of occult paroxysmal atrial fibrillation in cryptogenic strokes detected by long-term noninvasive cardiac monitoring. Stroke Res Treat. 2011;2011:172074. doi:10.4061/2011/172074

8. Miller DJ, Khan MA, Schultz LR, et al. Outpatient cardiac telemetry detects a high rate of atrial fibrillation in cryptogenic stroke. J Neurol Sci. 2013;324(1-2):57-61. doi:10.1016/j.jns.2012.10.001

9. Tayal AH, Tian M, Kelly KM, et al. Atrial fibrillation detected by mobile cardiac outpatient telemetry in cryptogenic TIA or stroke. Neurology. 2008;71(21):1696-1701. doi:10.1212/01.wnl.0000325 059.86313 .31

10. Rabinstein AA, Fugate JE, Mandrekar J, et al. Paroxysmal atrial fibrillation in cryptogenic stroke: a case-control study. $J$ Stroke Cerebrovasc Dis. 2013;22(8):1405-1411. doi:10.1016/j. jstrokecerebrovasdis.2013.05.013

11. Stewart S, Hart CL, Hole DJ, McMurray JJ. A population-based study of the long-term risks associated with atrial fibrillation: 20-year follow-up of the Renfrew/Paisley study. Am J Med. 2002;113(5):359-364. doi:10.1016/S0002-9343(02)01236-6

12. Wolf PA, Abbott RD, Kannel WB. Atrial fibrillation as an independent risk factor for stroke: the Framingham Study. Stroke. 1991;22 (8):983-988. doi:10.1161/01.STR.22.8.983

13. CETF. Cardiogenic brain embolism. The second report of the cerebral embolism task force. Arch Neurol. 1989;46(7):727-743. doi:10.1001/ archneur.1989.00520430021013

14. AFWG. Independent predictors of stroke in patients with atrial fibrillation: a systematic review. Neurology. 2007;69(6):546-554. doi:10.1212/01.wnl.0000267275.68538.8d 
15. Barrett PM, Komatireddy R, Haaser S, et al. Comparison of 24-hour Holter monitoring with 14-day novel adhesive patch electrocardiographic monitoring. Am J Med. 2014;127(1):95.e11-97. doi:10.1016/ j.amjmed.2013.10.003

16. Camm AJ, Kirchhof P, Lip GY, et al. Guidelines for the management of atrial fibrillation: the task force for the management of atrial fibrillation of the European Society of Cardiology (ESC). Eur Heart J. 2010;31(19):2369-2429. doi:10.1093/eurheartj/ehq278

17. January CT, Wann LS, Alpert JS, et al. AHA/ACC/HRS guideline for the management of patients with atrial fibrillation: executive summary: a report of the American College of Cardiology/American Heart Association Task Force on practice guidelines and the Heart Rhythm Society. Circulation. 2014;130(23):2071-2104. doi:10.1161/ CIR.0000000000000040

18. Christensen LM, Krieger DW, Højberg S, et al. Paroxysmal atrial fibrillation occurs often in cryptogenic ischaemic stroke. Final results from the Surprise study. Eur J Neurol. 2014;21(6):884-889. doi:10.1111/ene. 12400

19. Sanna T, Diener HC, Passman RS, et al. Cryptogenic stroke and underlying atrial fibrillation. $N$ Engl J Med. 2014;370 (26):2478-2486. doi:10.1056/NEJMoa1313600

20. Hart RG, Pearce LA, Aguilar MI. Meta-analysis: antithrombotic therapy to prevent stroke in patients who have nonvalvular atrial fibrillation. Ann Intern Med. 2007;146(12):857-867.

21. Jauch EC, Saver JL, Adams HP Jr, et al. Guidelines for the early management of patients with acute ischemic stroke: a guideline for healthcare professionals from the American Heart Association/ American Stroke Association. Stroke. 2013;44(3):870-947.

22. Healey JS, Connolly SJ, Gold MR, et al. Subclinical atrial fibrillation and the risk of stroke. $N$ Engl J Med. 2012;366(2):120-129. doi:10.1056/NEJMoa1105575

23. Camm AJ, Corbucci G, Padeletti L. Usefulness of continuous electrocardiographic monitoring for atrial fibrillation. Am J Cardiol. 2012;110(2):270-276. doi:10.1016/j.amjcard.2012.03.021

24. Chew DS, Rennert-May E, Quinn FR, et al. Economic evaluation of extended electrocardiogram monitoring for atrial fibrillation in patients with cryptogenic stroke. Int $J$ Stroke. 2020;34:1747493020974561.

25. Culebras A, Messe SR, Chaturvedi S, Kase CS, Gronseth G. Summary of evidence-based guideline update: prevention of stroke in nonvalvular atrial fibrillation: report of the Guideline Development Subcommittee of the American Academy of Neurology. Neurology. 2014;82(8):716-724. doi:10.1212/WNL.0000000000000145

26. Galli A, Ambrosini F, Lombardi F. Holter monitoring and loop recorders: from research to clinical practice. Arrhythm Electrophysiol Rev. 2016;5(2):136-143. doi:10.15420/ AER.2016.17.2

27. Kamel H, Easton JD, Johnston SC, Kim AS. Cost-effectiveness of apixaban vs warfarin for secondary stroke prevention in atrial fibrillation. Neurology. 2012;79(14):1428-1434. doi:10.1212/ WNL.0b013e31826d5fe8

28. Coyle D, Coyle K, Cameron C, et al. Cost-effectiveness of new oral anticoagulants compared with warfarin in preventing stroke and other cardiovascular events in patients with atrial fibrillation. Value Health. 2013;16(4):498-506. doi:10.1016/j.jval.2013.01.009

29. Sposato LA, Cipriano LE, Saposnik G, Ruiz Vargas E, Riccio PM, Hachinski V. Diagnosis of atrial fibrillation after stroke and transient ischaemic attack: a systematic review and meta-analysis. Lancet Neurol. 2015;14(4):377-387. doi:10.1016/S1474-4422(15)70027-X

30. Ziegler PD, Rogers JD, Ferreira SW, et al. Real-world experience with insertable cardiac monitors to find atrial fibrillation in cryptogenic stroke. Cerebrovasc Dis. 2015;40(3-4):175-181. doi:10.1159/ 000439063
31. Favilla CG, Ingala E, Jara J, et al. Predictors of finding occult atrial fibrillation after cryptogenic stroke. Stroke. 2015;46(5):1210-1215. doi:10.1161/STROKEAHA.114.007763

32. BLS. Bureau of Labor Statistics, U.S. Department of labor. Medical care consumer price index annual average 2010 through 2020, Series Name: medical care in U.S. city average, all urban consumers, not seasonally adjusted; 2021. Available from: https://www.bls.gov/cpi/. Accessed May 20, 2021.

33. Sawyer LM, Witte KK, Reynolds MR, et al. Cost-effectiveness of an insertable cardiac monitor to detect atrial fibrillation in patients with cryptogenic stroke. J Comp Eff Res. 2021;10(2):127-141. doi:10.2217/cer-2020-0224

34. Diamantopoulos A, Sawyer LM, Lip GY, et al. Cost-effectiveness of an insertable cardiac monitor to detect atrial fibrillation in patients with cryptogenic stroke. Int J Stroke. 2016;11(3):302-312. doi:10.1177/1747493015620803

35. Maervoet J, Bossers N, Borge RP Jr, Hilpert ST, van Engen A, Smala A. Use of insertable cardiac monitors for the detection of atrial fibrillation in patients with cryptogenic stroke in the United States is cost-effective. J Med Econ. 2019;22(11):1221-1234. doi:10.1080/13696998.2019.1663355

36. Tsang JP, Mohan S. Benefits of monitoring patients with mobile cardiac telemetry (MCT) compared with the Event or Holter monitors. Med Devices. 2013;7:1-5.

37. Kaura A, Sztriha L, Chan FK, et al. Early prolonged ambulatory cardiac monitoring in stroke (EPACS): an open-label randomised controlled trial. Eur J Med Res. 2019;24(1):25. doi:10.1186/s40001019-0383-8

38. Yong JH, Thavorn K, Hoch JS, et al. Potential cost-effectiveness of ambulatory cardiac rhythm monitoring after cryptogenic stroke. Stroke. 2016;47(9):2380-2385. doi:10.1161/ STROKEAHA.115.011979

39. Barral M, Rabier H, Termoz A, et al. Patients' productivity losses and informal care costs related to ischemic stroke: a French populationbased study. Eur J Neurol. 2021;28(2):548-557. doi:10.1111/ ene. 14585

40. Aspirin_Drugs.com; 2021. Available from: https://www.drugs.com/ price-guide/aspirin. Accessed May 25, 2021.

41. Wang YP, Kehar R, Iansavitchene A, Lazo-Langner A. Bleeding risk in nonvalvular atrial fibrillation patients receiving direct oral anticoagulants and warfarin: a systematic review and meta-analysis of observational studies. TH Open. 2020;4(3):e145-e152. doi:10.1055/ s-0040-1714918

42. Shireman TI, Wang K, Saver JL, et al. Cost-effectiveness of solitaire stent retriever thrombectomy for acute ischemic stroke: results from the SWIFT-PRIME trial (Solitaire with the intention for thrombectomy as primary endovascular treatment for acute ischemic stroke). Stroke. 2017;48(2):379-387. doi:10.1161/ STROKEAHA.116.014735

43. Schweizer ML, Cullen JJ, Perencevich EN, Vaughan Sarrazin MS Costs associated with surgical site infections in veterans affairs hospitals. JAMA Surg. 2014;149(6):575-581. doi:10.1001/ jamasurg.2013.4663

44. Li A, Carlson JJ, Kuderer NM, et al. Cost-effectiveness analysis of low-dose direct oral anticoagulant (DOAC) for the prevention of cancer-associated thrombosis in the United States. Cancer. 2020;126(8):1736-1748. doi:10.1002/cncr.32724

45. Afzal MR, Casmer A, Buck B, et al. Incidence and risk factors for early explantation of subcutaneous cardiac rhythm monitors. JACC Clin Electrophysiol. 2020;6(14):1858-1860. doi:10.1016/j. jacep.2020.08.031

46. Laine L. Bleeding with direct oral anticoagulants: the gastrointestinal tract and beyond. Clin Gastroenterol Hepatol. 2017;15 (11):1665-1667. doi:10.1016/j.cgh.2017.06.041 


\section{Publish your work in this journal}

Medical Devices: Evidence and Research is an international, peerreviewed, open access journal that focuses on the evidence, technology, research, and expert opinion supporting the use and application of medical devices in the diagnosis, monitoring, treatment and management of clinical conditions and physiological processes. The identification of novel devices and optimal use of existing devices which will lead to improved clinical outcomes and more effective patient management and safety is a key feature of the journal The manuscript management system is completely online and includes a very quick and fair peer-review system. Visit http:// www.dovepress.com/testimonials.php to read real quotes from published authors.

Submit your manuscript here: https://www.dovepress.com/medical-devices-evidence-and-research-journal 